\title{
APLICAÇÃO DE SISTEMA ALINHADOR INTELIGENTE PARA TRANSPORTADOR DE CORREIA E SEUS BENEFÍCIOS*
}

Anderson Rosa Pereira ${ }^{1}$

\section{Resumo}

A constante busca pelo aumento contínuo de produção e redução de paradas não programadas em transportadores, tem gerado demanda para equipamentos inteligentes dotados da capacidade de corrigir os constantes problemas de desalinhamento dos TCs. Os métodos hoje utilizados para corrigir este problema são prioritariamente passivos, o que impossibilita uma intervenção mais direta, precisa, automática e efetiva no posicionamento da correia. Esta publicação descreve o funcionamento e os resultados obtidos com a integração do sistema Alinhador Inteligente para Transportador de Correia AITC em um transportador de minério de ferro com vasto histórico de problemas de desalinhamento. Assim, a linha principal deste artigo mostra através de um exemplo prático os benefícios e ganhos mensurados com a aplicação do Alinhador Inteligente para Transportador de Correia.

Palavras-chave: Sistema alinhador inteligente para transportador de correia; Redução de paradas não programadas em transportadores de correia; Controle automático da posição da correia transportadora.

\section{APPLICATION OF CONVEYOR BELT GUIDANCE SYSTEM AND ITS BENEFITS}

\section{Abstract}

The constant search for the continuous increase of the production and the reduction of the non-programmed stops on belt conveyor has generated a demand for intelligent equipment able of correcting constant problems of misalignment of CBs. The methods that we currently use to correct this problem are mainly passives, which makes impossible a more direct, precise, automatic and effective intervention in the positioning of the belt. This publication describes the functioning and the results achieved with the integration of the Conveyor Belt Guidance System, or only CBGS, in an iron ore belt conveyor with an extensive track record of misalignment. Therefore, the main line of this article shows through practical example the advantages and measured gains by applying the Conveyor Belt Guiding System.

Keywords: Conveyor belt guidance system; Reduction of the non-programmed stops on belt conveyor; Automatic control of the positioning of the conveyor belt.

1 Engenheiro eletricista, coordenador de vendas, departamento de engenharia, EMH, Belo Horizonte, MG, Brasil. 


\section{INTRODUÇÃO}

A EMH trouxe a tecnologia de alinhamento de tiras metálicas da siderurgia para o mundo da mineração. Utilizando o know how e equipamentos de ponta produzidos na matriz alemã, EMG Automation, foi possível desenvolver uma solução segura e eficiente para o problema de desalinhamento de correia transportadora. O sistema Alinhador Inteligente para Transportador de Correia (AITC) foi desenvolvido com componentes robustos e pensado para trabalhar no ambiente hostil da mineração. Com construção sob encomenda para transportadores diversos, tanto em seções de carga como de retorno, é possível o controle em malha fechada da posição da correia em seções críticas, objetivando prevenir as falhas provocadas por desalinhamento em TCs.

Este trabalho apresenta um estudo de caso aplicado em uma grande empresa brasileira de mineração, onde, por meio da utilização do sistema alinhador inteligente para transportador de correia (AITC), foi possível banir os problemas de desalinhamento de correia em um transportador crítico de uma usina de beneficiamento.

\section{DEFINIÇÃO DE TRANSPORTADOR DE CORREIA E PRINCIPAIS PROBLEMAS}

\subsection{Definição de Transportador de Correia e Principais Defeitos}

Por definição, um transportador de correia é um conjunto de componentes mecânicos e elétricos, destinado ao transporte de diferentes tipos de materiais.

Os principais componentes são:

Correia: Também chamada de lona, responsável pelo contato com o material a ser transportado. Ela é formada por três partes, são elas: carcaça, cobertura superior e cobertura inferior.

Tambores: Construídos normalmente em aço, têm como função principal tracionar a correia para o funcionamento do transportador, sendo neste caso, papel exercido pelo tambor motriz, onde está acoplada a motorização. Com a movimentação da correia movem-se também os demais componentes e o tambor movido, que promove o seu apoio.

Roletes de carga e retorno: Conjunto de rolos, no qual se apoia o trecho carregado e de retorno da correia transportadora.

Roletes auto-alinhantes: Conjunto de rolos dotado de mecanismos giratórios acionados pela própria correia transportadora ou por dispositivo eletro/hidráulico, de modo a controlar o deslocamento lateral da mesma. São utilizados tanto no trecho carregado quanto no de retorno.

Esticadores: Tem como principal função garantir a tensão conveniente para o acionamento da correia, e, além disso, absorver as variações no comprimento da correia causadas pelas mudanças de temperatura, oscilações de carga, tempo de trabalho e etc.

De maneira simplificada, após o material ser colocado na correia o tambor de acionamento é o responsável pela transferência de uma força para movimentação da mesma. O tambor livre recebe uma tração da correia, a qual está apoiada em roletes, que servem para suportá-la e guia-la. O material direcionado e descarregado através do chute ou calha.

Quando analisamos o comportamento de um transportador de correias em relação a falhas podemos citar como os principais agentes causadores de paradas não 
programadas: Cabo de aço rompido, deslocamento, quebra, sucata metálica, folgas e o principal, desalinhamento da correia.

\subsection{Dasalinhamento de Correia e suas Principais Causas}

É muito comum acompanharmos correias transportadoras trabalhando com excessivo desalinhamento e geralmente tocando agressivamente os roletes laterais e principalmente as estruturas de sustentação do transportador.

Assim, o desalinhamento da correia é um dos grandes fatores que reduzem significativamente a vida útil das correias, necessitando de um acompanhamento diferenciado de suas causas.

Abaixo segue alguns itens que influenciam diretamente no defeito de desalinhamento, assim precisam de um acompanhamento mais apurado:

\subsubsection{Roletes}

Os roletes devem estar perpendiculares em relação à linha de centro do transportador, limpos e girando sem obstruções. Variações de nível, posição angular de referência, roletes travados ou girando com dificuldades tem forte impacto no alinhamento global da correia.

\subsubsection{Tambores}

Nas mesmas condições dos roletes os tambores devem sempre estar perpendiculares à linha de centro do transportador e paralelos entre si. A limpeza do tambor também é essencial caso contrário o excesso de material pode causar alterações de diâmetro e por consequência desalinhamento de correia.

\subsubsection{Estrutura metálica}

Tanto o alinhamento como o nivelamento da estrutura base do transportador tem influencia direta e significativa no controle de alinhamento da correia.

\subsubsection{Chutes de alimentação}

A alimentação do transportador quando feita de forma descentralizada causa desalinhamento, pois devido ao acumulo de material fora do centro da correia este peso cria uma tendência que altera a acomodação da correia nos roletes de carga.

\section{PRINCIPIO DE FUNCIONAMENTO DO ALINHADOR INTELIGENTE PARA TRANSPORTADOR DE CORREIA - AITC}

A série AITC é constituída por Alinhadores Inteligentes para Transportadores de Correia.

Utilizando componentes construídos para aplicações severas e ambientes agressivos, os Alinhadores Inteligentes AITC têm variações construtivas para todos os padrões de transportadores de correia.

O conjunto básico pode ser visto na figura 1 : 


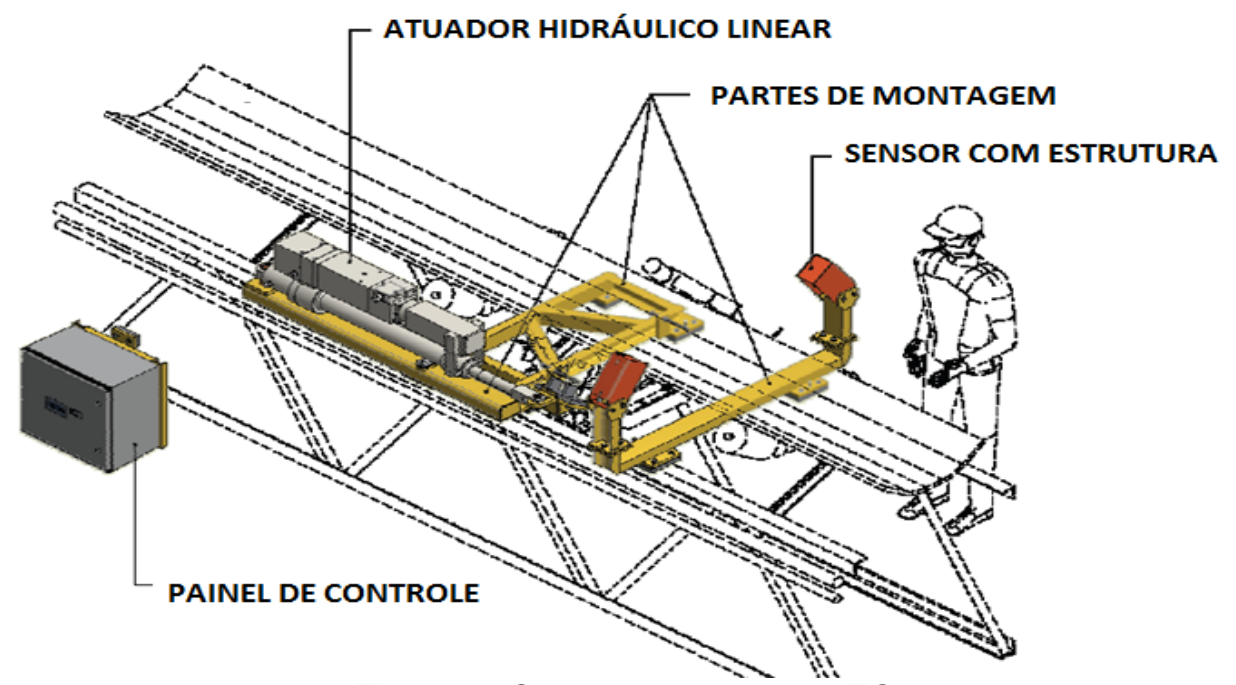

Figura 1. Conjunto básico do ÄITC

O sistema AITC é composto dos seguintes itens:

- Sensores

Com alto grau de proteção, IP67, são especificados levando-se em consideração a agressividade do ambiente, portanto são extremamente robustos.

Tem a função de detectar com alta precisão a posição da correia em relação ao centro do transportador. A posição indicada de montagem dos sensores para correia de retorno pode ser vista na figura 2.

- Painel do sistema

O painel (figura 3) aloca os circuitos de comando/alimentação e o PLC de controle. Este último recebe os dados gerados pelos sensores que verificam a posição da correia, interpreta estes dados e então aciona o atuador eletro-hidráulico, movimentando assim de forma controlada, o rolete alinhador.

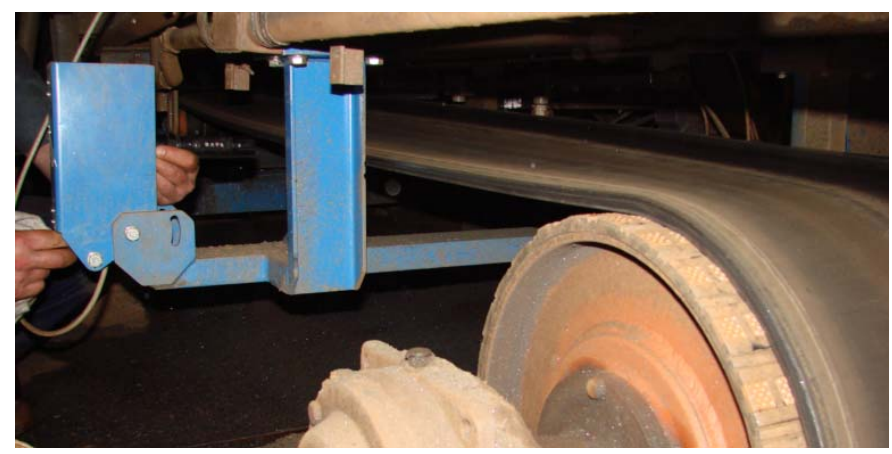

Figura 2. Suporte dos sensores de posição

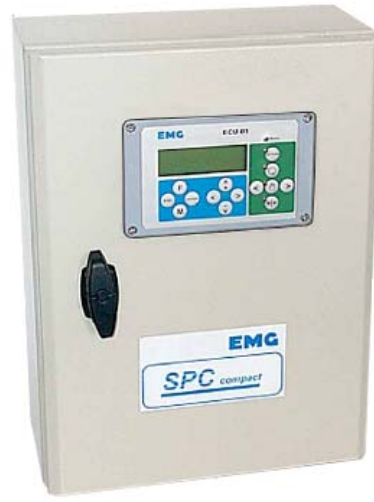

Figura 3. Painel de controle

\section{- Atuador eletro-hidráulico}

O atuador hidráulico compacto linear (figura 4) é robusto, tem alto grau de proteção, IP66, não necessita de reabastecimento de óleo nem de ventilação forçada. É imune a sujeira, tem projeto compacto e sua integração é extremamente simples. $O$ conjunto de válvulas e todo o sistema hidráulico foram reduzidos e enclausurados em uma adaptação direta com o cilindro atuador. 


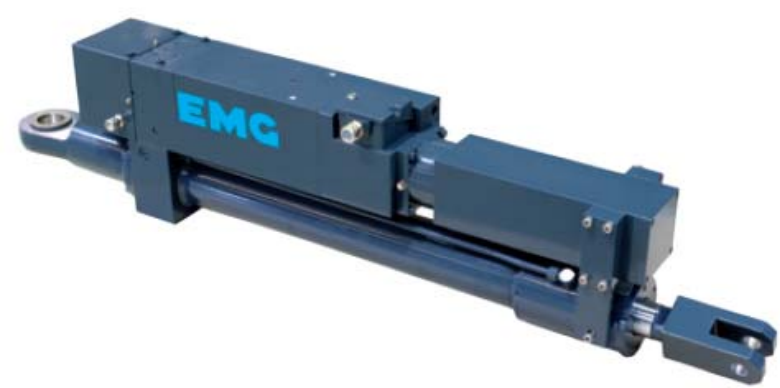

Figura 4. Atuador hidráulico compacto linear

\section{ESTUDO DE CASO}

O projeto descrito a seguir foi desenvolvido em uma correia transportadora crítica, que atende uma usina de beneficiamento de uma mina de grande porte no Pará.

O início do trabalho se deu com o levantamento de dados para identificar as principais causas de parada de uma usina de beneficiamento.

O período base de análise, que gerou os gráficos 1 a 5 foi de 90 dias (01/10/2013 a 31/12/2013).

\subsection{Análise para Identificar Principal Causador de Paradas da Usina de Beneficiamento 1}

Em relação às paradas da Usina de beneficiamento 1 foi possível observar:

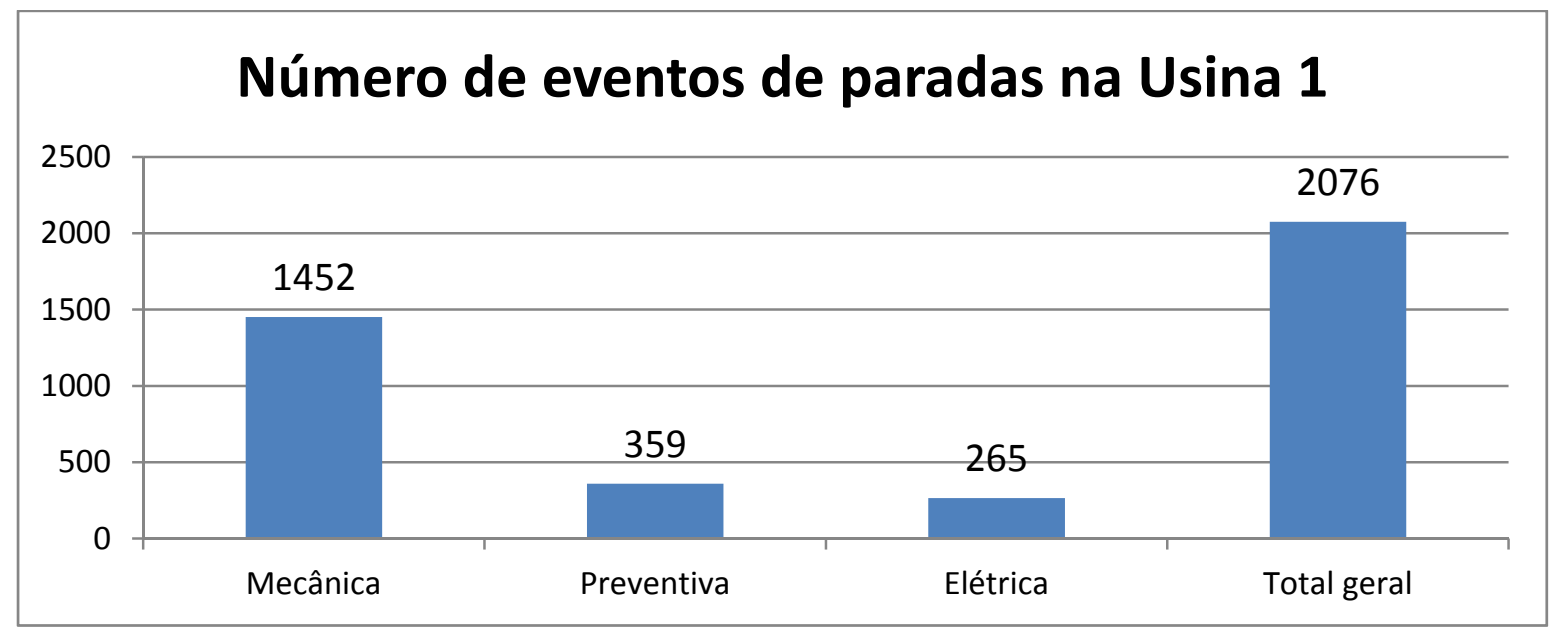

Figura 5. Eventos causadores de paradas não programadas na Usina 1.

Assim, as paradas mecânicas representaram mais de $65 \%$ do total de eventos de paradas da Usina de beneficiamento 1.

Fazendo uma análise mais detalhada das paradas mecânicas observadas na Figura 5, foi observado: 


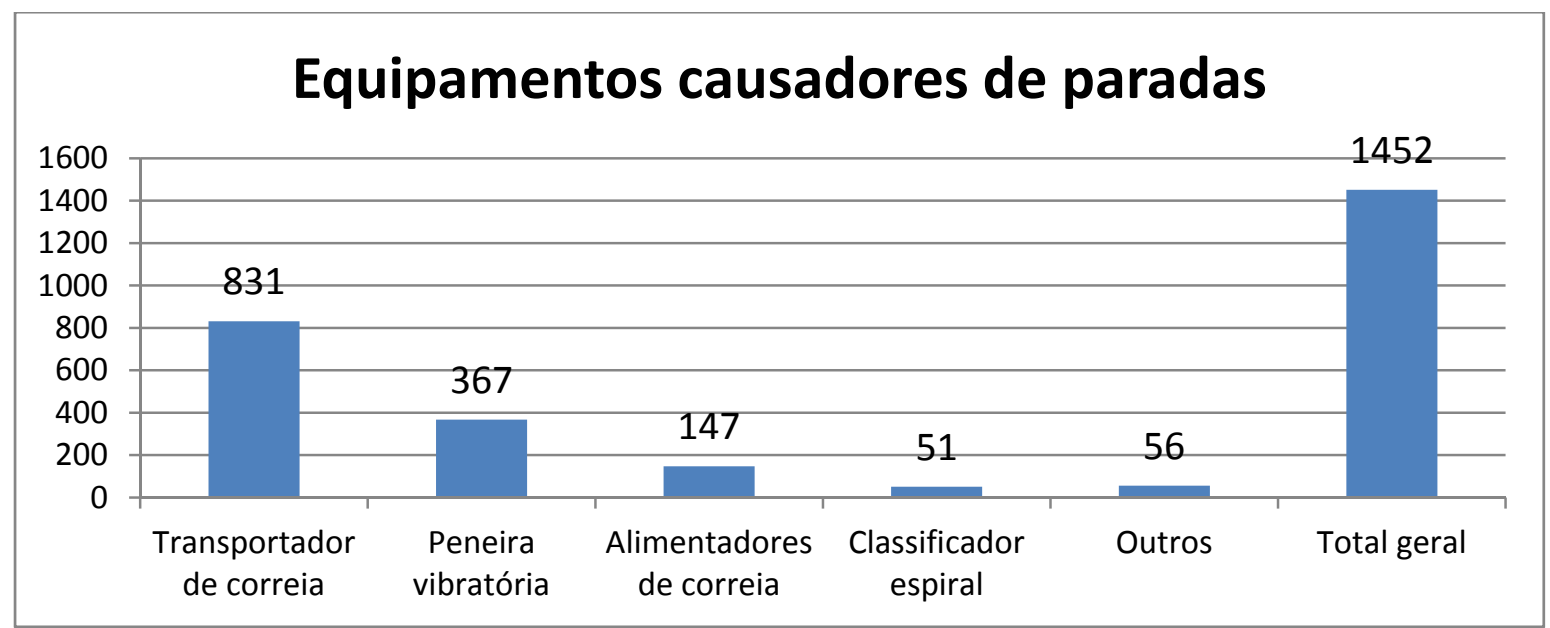

Figura 6. Equipamentos causadores de paradas.

Assim, mais de $55 \%$ das paradas mecânicas da Usina de beneficiamento 1 foram causadas por problemas em transportadores de correia.

É importante notar que a Usina de beneficiamento 1 conta com diversos circuitos de transportadores de correia, então:

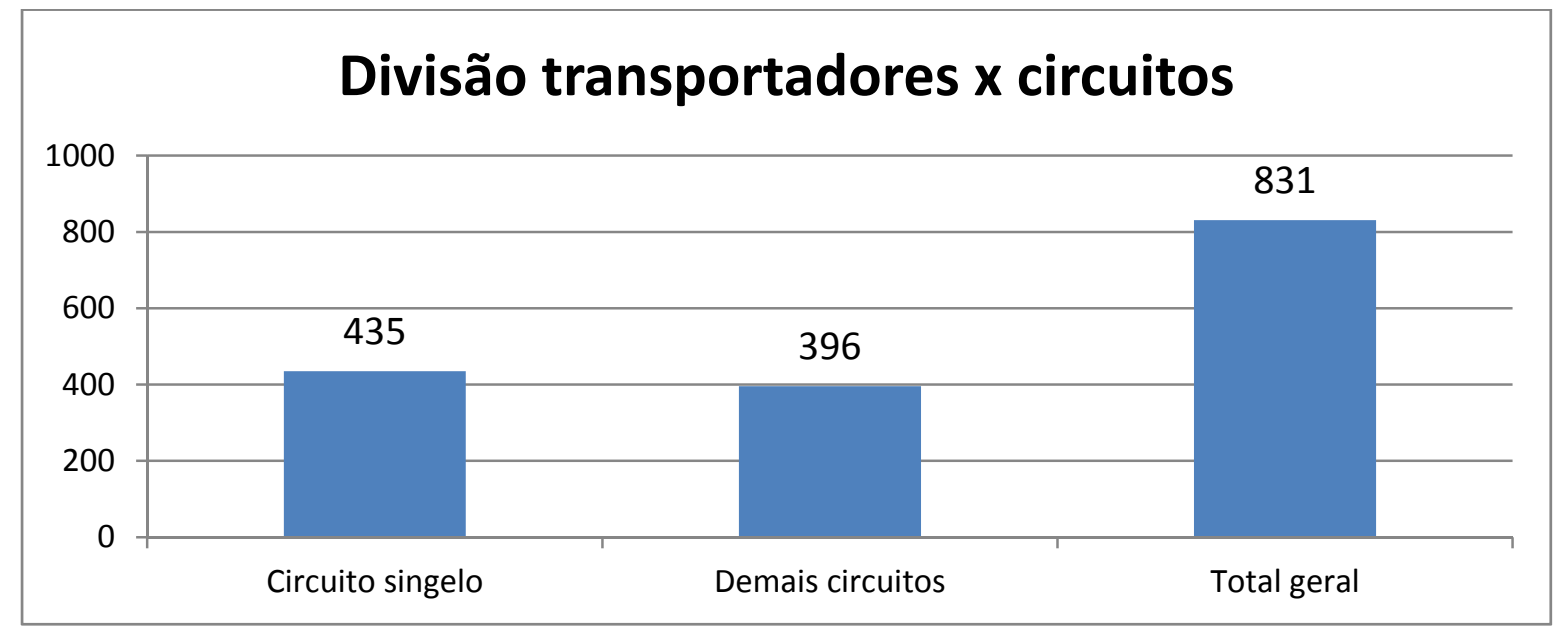

Figura7. Divisão de eventos de paradas por circuitos que atendem a Usina 1.

No gráfico acima foi possível observar que o circuito singelo é responsável por mais de $50 \%$ dos eventos de paradas gerais.

Voltando a análise para o circuito singelo temos: 


\section{Paradas mecânicas em transportadores do circuito singelo}

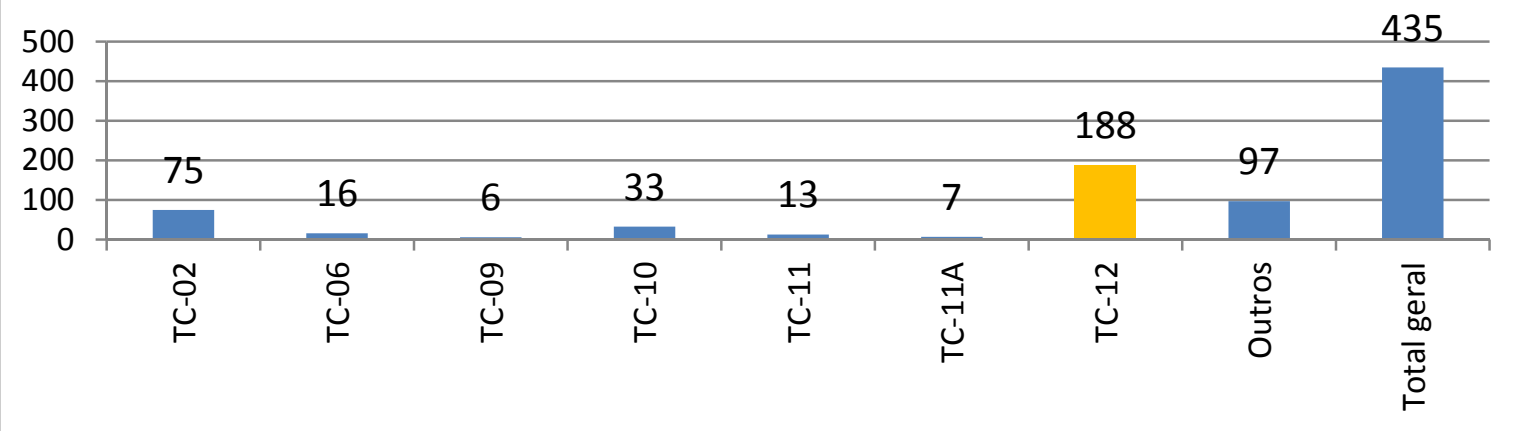

Figura 8. Eventos de paradas mecânicas em transportadores do circuito singelo.

Quando a Figura 8 é analisada é possível perceber que o transportador TC-12 (destacado no gráfico acima) responde por mais de $40 \%$ das paradas do circuito singelo.

Ao analisar somente os eventos de paradas do transportador TC-12 é possível observar:

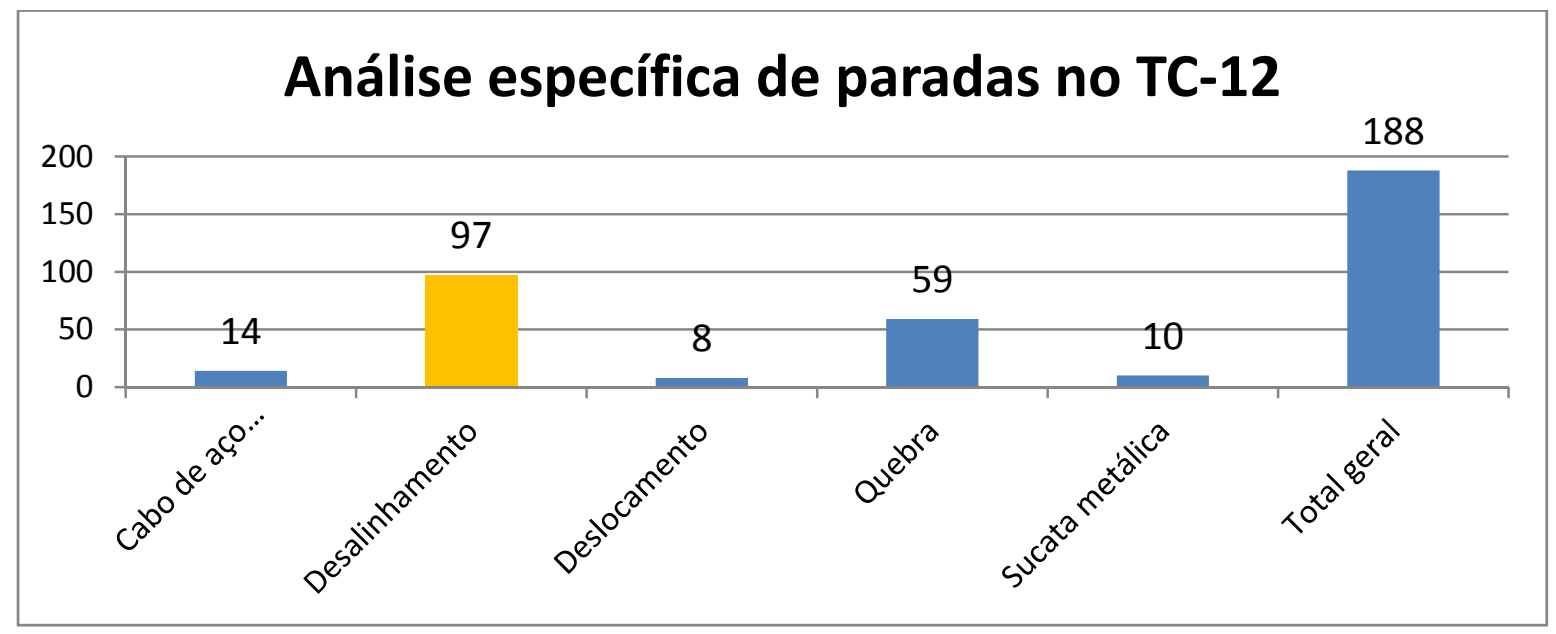

Figura 9. Análise específica de paradas no TC-12.

Assim, mais de $50 \%$ das paradas do transportador TC-12 são geradas por problemas de desalinhamento.

Estes 97 eventos de paradas do transportador TC-12 geraram 29 horas e 46 minutos de paradas não programadas na Usina de beneficiamento 1 .

\subsection{Análise Específica do Problema de Desalinhamento do TC-12}

Uma vez que o problema de desalinhamento de correia no transportador TC-12 foi identificado como principal causador de paradas não programadas da Usina de beneficiamento 1, uma análise mais específica foi feita tendo como principal objetivo eliminar as paradas deste transportador causadas por problema de desalinhamento. Ao desenvolver um diagrama de causa e efeito foi observado como principais causas do problema de desalinhamento:

- Acúmulo de material entre o tambor e a correia.

Ocorre principalmente devido ao desgaste das lâminas dos raspadores. 
- Projeção descentralizada do material durante a alimentação.

Ocorre principalmente devido a configuração dos chutes de alimentação.

- Ineficiência do dispositivo de alinhamento tradicional.

Os roletes auto alinhadores tradicionais não tem capacidade suficiente para corrigir a posição da correia nos pontos críticos.

Assim, modificar o sistema de limpeza ou a configuração dos chutes de alimentação se provou inviável, então o cliente investiu na instalação de um sistema alinhador inteligente para transportador de correia.

\subsection{Adaptação do Sistema Alinhador Inteligente para Transportador de Correia}

O transportador TC-12 tem o comprimento de pouco mais de $100 \mathrm{~m}$ e usa correia de $1600 \mathrm{~mm}$, tem velocidade nominal de $4,5 \mathrm{~m} / \mathrm{s}$, capacidade nominal de $9.900 \mathrm{t} / \mathrm{h}$ e é equipado com 15 chutes de carregamento.

O croqui básico do transportador pode ser visto abaixo:

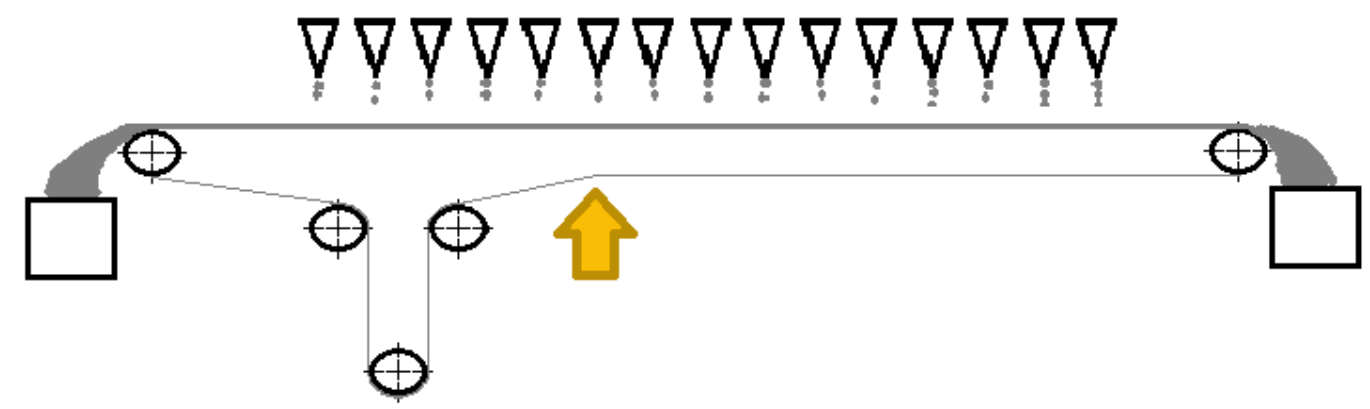

Figura 10. Croqui básico do transportador de correia TC-12

Após análise da equipe de engenharia da $\mathrm{EMH}$, foi sugerido ao cliente a instalação de um sistema AITC no ponto sinalizado pela seta amarela na Figura 10.

O projeto básico do AITC integrado neste transportador pode ser visto abaixo:

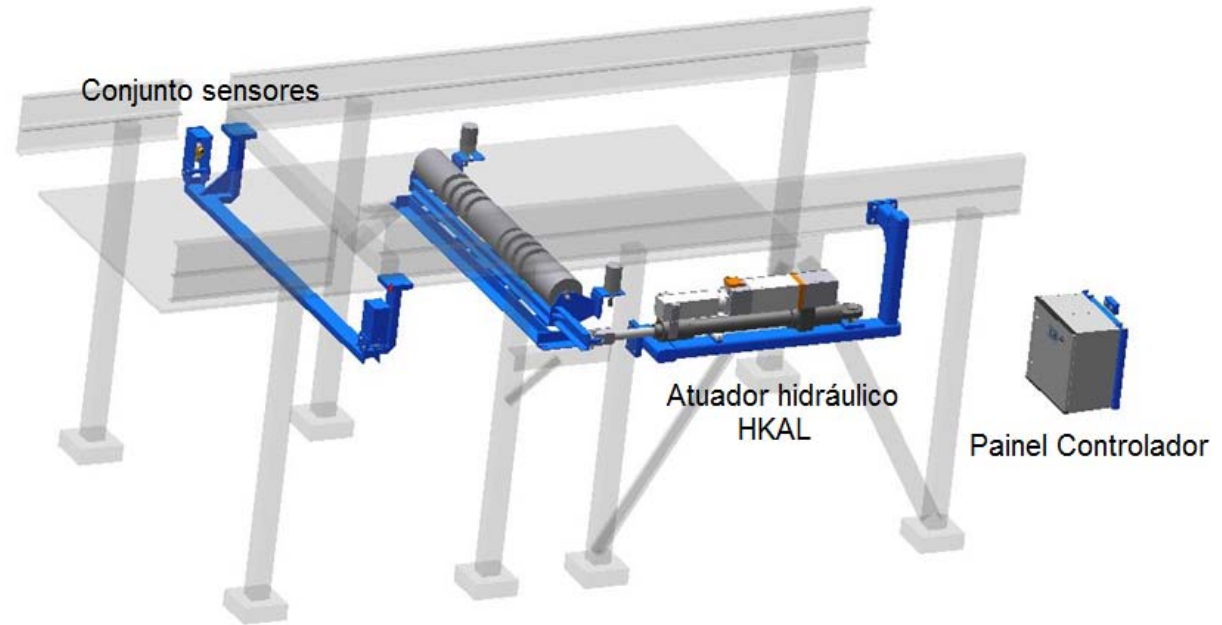

Figura 11. Projeto básico de integração do AITC ao transportador

\subsection{Análise dos Resultados Após Instalação do Sistema AITC}

O gráfico da Figura 12 mostra a análise específica de paradas no TC-12 antes da instalação do AITC. Onde o período da coleta de dados foi entre os dia 01/10/2013 a 31/12/2013 (90 dias). 
Neste período o defeito "desalinhamento de correia" foi responsável por 97 eventos de paradas, ou $48 \%$ do total.

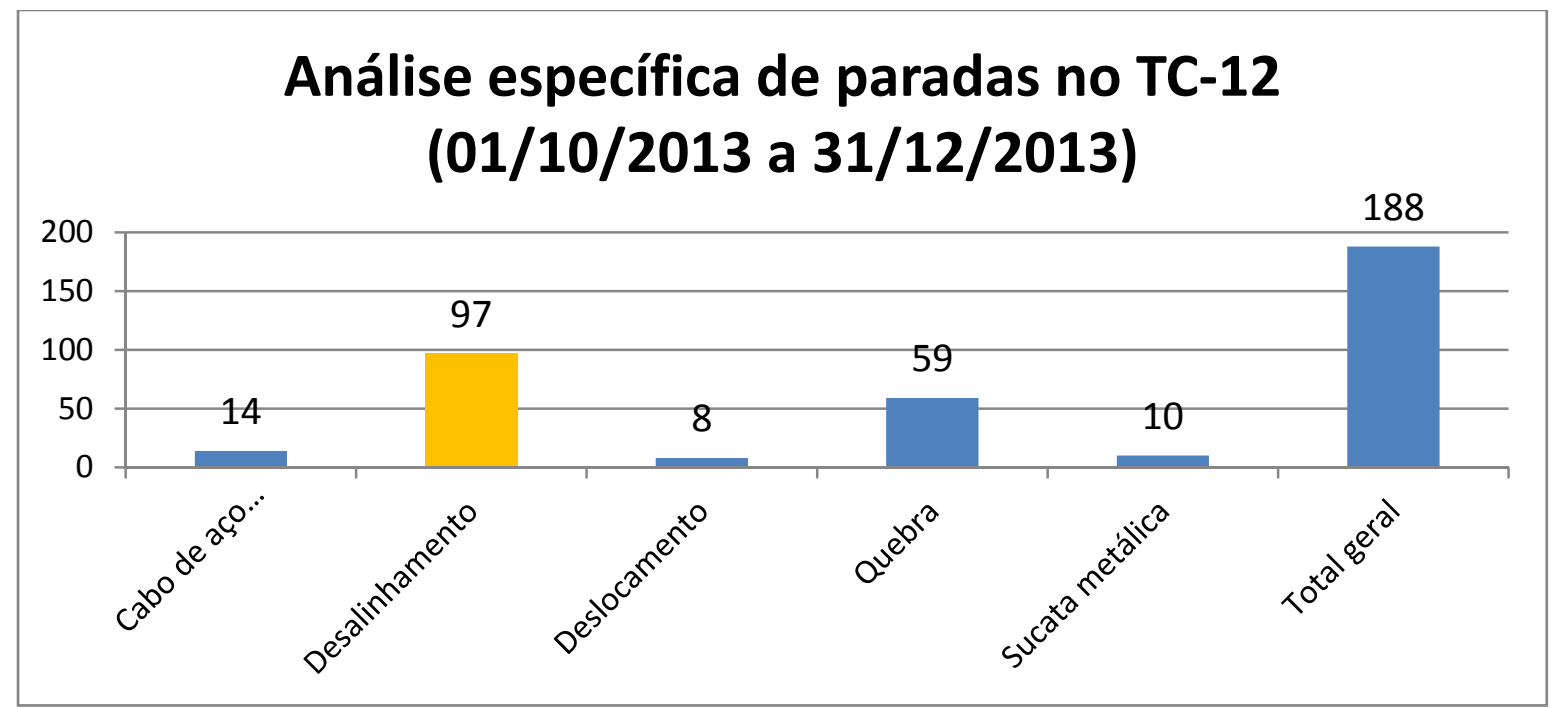

Figura 12. Análise específica de paradas no TC-12 antes da instalação do AITC

A Figura 13 mostra a análise específica de paradas para o transportador TC-12 após a instalação do AITC.

Para manter a mesma base de análise, o mesmo período de tempo foi respeitado. Assim, a coleta de dados foi feita entre os dias 15/02/2014 a 15/05/2014 (90 dias).

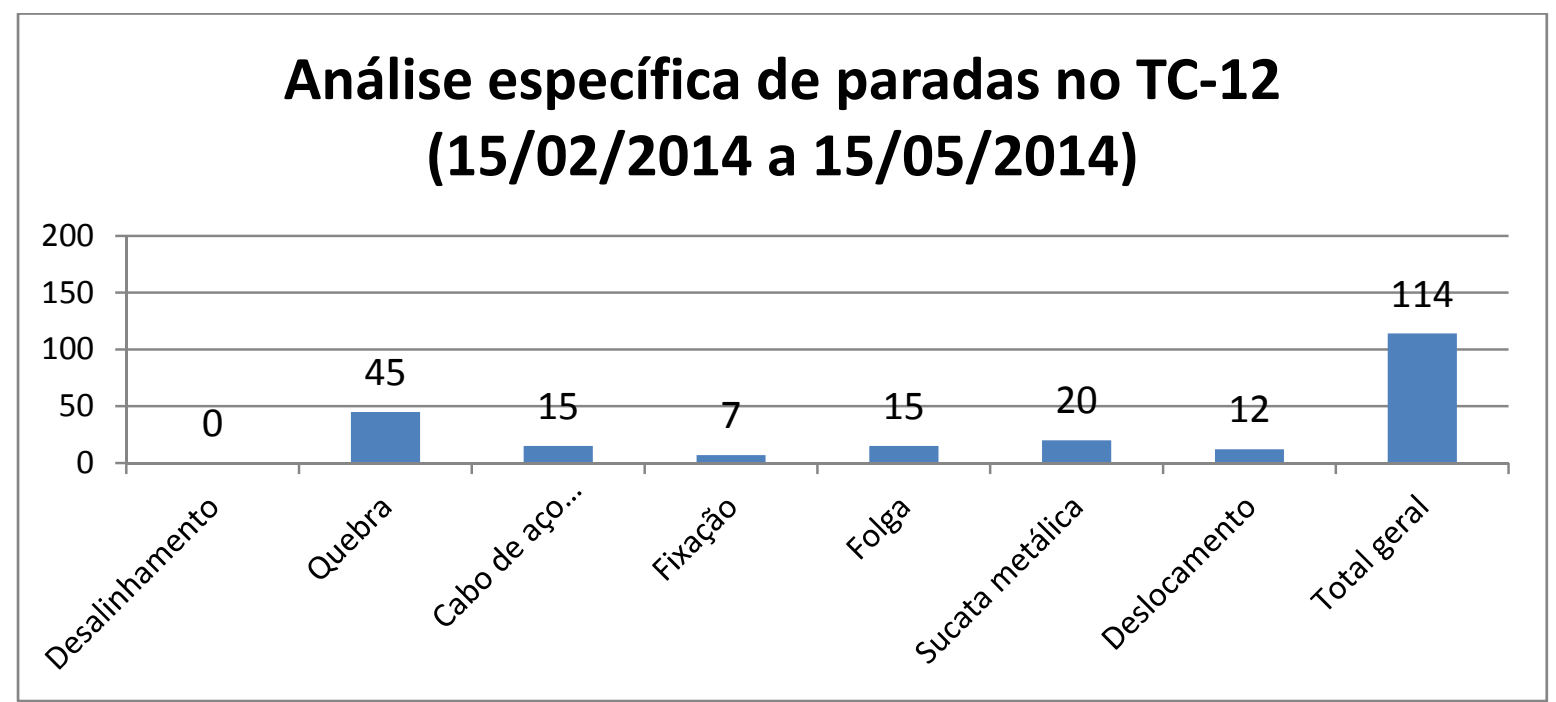

Figura 13. Análise específica de paradas no TC-12 depois da instalação do AITC

Como pode ser visualizado no gráfico da Figura 13, após a instalação do AITC, não houve nenhum evento de parada no transportador TC-12 causado por problema de desalinhamento de correia.

\section{CONCLUSÃO}

Portanto, fica comprovado que após a instalação do sistema AITC, considerando-se o mesmo período de análise de 90 dias, ocorrido no início de 2014, a eficiência do sistema alinhador inteligente se torna evidente, uma vez que nenhuma parada por defeito de desalinhamento foi contatada no transportador analisado. 
As paradas ocorridas nos 3 meses avaliados, antes da instalação do AITC, geraram 29 horas e 46 minutos de paradas não programadas. Com estas paradas na usina de beneficiamento 1 o cliente perdeu aproximadamente $R \$ 9$ milhões de reais em produção.

Ainda pode ser ressaltado que um ganho de segurança significativo pode ser apontado, uma vez que foi eliminada a exposição de colaboradores aos riscos de manutenção não programada no TC para corrigir os problemas de desalinhamento de correia.

Isto mostra que a instalação do sistema AITC gera ganhos no tocante à estabilidade de um transportador de correia, na medida que resolve os problemas de desalinhamento, consequentemente reduzindo as paradas por falha e aumentando a segurança dos colaboradores envolvidos na manutenção do equipamento.

\section{REFERÊNCIAS}

1 Calijorne, Alexandre. Aspectos essenciais em sistemas para longa distância. 2011 [acesso em 07 Abril 2015];01:01-04. Disponível em: http://www.revistaminerios.com.br/Publicacoes/3505/Aspectos_essenciais_em_sistemas para_longa_distancia.aspx

2 Faço. Manual de transportadores de correia. São Paulo: $4^{\mathrm{a}}$ ed.

3 Como anda a vida útil de suas correias transportadoras. 2008. [acesso em 07 abr. 2015];01:01-01. Disponível em:

http://www.metso.com/inetMinerals/Brazil/mm_Brazilcontent.nsf/WebWID/WTB-0806032256F-DF7DF/\$File/04_Maio_08_PTcompac.pdf

4 Dariusz, Mazurkiewicz. Computer-aided maintenance and reliability management systems for conveyor belts. Maintenance and Reliability Vol.16, No. 3, 2014 